\title{
Cultura Cultura
}

Vol. 23 | 2006

Ideia(s) de Tempo(s)

\section{A qualificação messiânica do tempo}

O caso de uma fórmula temporal no primeiro evangelho do cânone cristão

A messianic qualification of time. The case of a time formula on the first Gospel in christian canon

José Tolentino Mendonça

\section{CpenEdition}

\section{Journals}

Edição electrónica

URL: http://journals.openedition.org/cultura/1482

DOI: $10.4000 /$ cultura. 1482

ISSN: 2183-2021

\section{Editora}

CHAM - Centro de Humanidades

Edição impressa

Data de publição: 1 janeiro 2006

Paginação: 253-258

ISSN: 0870-4546

\section{Refêrencia eletrónica}

José Tolentino Mendonça, «A qualificação messiânica do tempo », Cultura [Online], Vol. 23 | 2006,

posto online no dia 11 abril 2014, consultado a 10 dezembro 2020. URL : http://

journals.openedition.org/cultura/1482; DOI : https://doi.org/10.4000/cultura.1482

Este documento foi criado de forma automática no dia 10 dezembro 2020

(c) CHAM - Centro de Humanidades / Centre for the Humanities 


\title{
A qualificação messiânica do tempo
}

\author{
o caso de uma fórmula temporal no primeiro evangelho do cânone \\ cristão
}

\author{
A messianic qualification of time. The case of a time formula on the first Gospel \\ in christian canon
}

José Tolentino Mendonça

1 Escrevia Fernando Pessoa, por interposta voz de um dos seus heterónimos: «Se, depois de eu morrer, quiserem escrever a minha biografia,/ Não há nada mais simples./ Tem só duas datas - a da minha nascença e a da minha morte». ${ }^{1}$ Neste «não há nada mais simples» há, talvez, um assomo de ironia, pois as datas têm mais significações e menos simplicidade do que aparentam.

2 A nós, por exemplo, o calendário ocidental indica que estamos no ano de 2005: 2005 depois de Jesus Cristo. É uma herança do cristianismo medievo a oficialização desta contagem do tempo. Os cristãos do período justiniano (séc. VI), convictos da singularidade histórica que Jesus representa, propõem que ele seja tomado como marco cronológico para tudo o que o antecedeu e para o que se lhe segue. o tempo deixa, assim, de ser uma categoria meramente contabilística e neutral (se é que alguma vez e em algum lado o foi!) e assume uma discreta conotação simbólica e teológica. Hoje, como sabemos, este calendário tornou-se praticamente universal, e vigora ou coexiste mesmo em contextos culturais alheios à tradição cristã.

3 Ora acontece que qualquer data, quer seja a do nascimento do poeta Fernando Pessoa, quer a data que sela o Jornal que podemos comprar, ou já comprámos, esta manhã, coloca-nos silenciosamente não apenas perante a questão do tempo, mas diante de uma mais primitiva interrogação: a do sentido do tempo. Podemos até concordar com Umberto Eco que afirma: «Esta obsessão por mensurar o tempo, esta ideia tão generalizada de calendarizar a existência são uma invenção moderna... Os povos da Antiguidade não tinham consciência do tempo». ${ }^{2}$ Mas não se pode dizer o mesmo se o debate for acerca daquilo que qualifica o tempo. 


\section{Do centro do espaço ao centro do tempo}

4 A determinação de um centro na espacialidade do mundo foi objecto de controvérsias e sobressaltos romanescos. Na actual Istambul, por exemplo,

ainda se aponta o exacto lugar na Àghia Sophia antiga, onde os bizantinos acreditavam estar o umbigo do mundo: era o lugar onde o Imperador era coroado e tinha o seu palanque. Mas essa é uma indicação móvel, sujeita à combinação de artificiosos nexos simbólicos, estratégias políticas, evoluções económicas... Não é por acaso que a experiência cristã havia contornado a noção de ubiquidade, tomando como autêntica pátria referencial não Jerusalém, nem Roma, mas sim esse perturbador, despojado e, afinal, poderoso não-lugar que é o sepulcro vazio (Mc 16, 6).

6 Mas como se colocou a questão do tempo no período das origens cristãs? De que forma as primeiras comunidades apreenderam e traduziram os acontecimentos relativos a Jesus através de uma modelação própria da temporalidade? Como emergiu esta consciência de que Jesus é o centro do tempo? Em que medida, a própria configuração narrativa que a experiência cristã assumiu, determinou, como diria Paul Ricoeur, ${ }^{3}$ uma refiguração da própria realidade temporal?

7 Um endereço interessante podia, efectivamente, ser este último. Toda a narrativa é uma operação sobre o tempo. Italo Calvino classificava-a como «encantamento que actua sobre o correr do tempo", ${ }^{4}$ aludindo aos necessários processos de manipulação temporal que o contar de uma história obriga. O tempo da história propriamente dito é cronológico e sucessivo, é o tempo factual. Mas narrar a história é seleccionar, intrometer cortes no tempo, acelerar ou retardar, introduzir uma nova ordem, sugerir modificações na frequência, avançar com investimentos semânticos. A narrativa é uma configuração que refigura o tempo histórico. A narrativa dá-nos o tempo histórico interpretado pelo tempo do discurso. Contar é interpretar. Deste modo, a perspectivação do tempo não se situa antes de tudo no que o texto diz, mas desenvolve-se prioritariamente a partir do que o texto é. Todo o texto é uma operação sobre o tempo, uma meditação sobre essa categoria da existência.

8 A este nível, seria muito interessante verificar a articulação que os textos neotestamentários, em registos diferentes, encenam entre o chamado tempo mortal e aquele monumental, entre o tempo puramente histórico e a cesura que representa o que ali se designa como tempo da salvação.

9 Mas, até por uma necessidade de adequação ao formato deste evento, optamos por uma fixação em redor de uma fórmula que refere "a plenitude do tempo", fórmula que nos aparece em três momentos do corpus textual do Novo Testamento cristão - na tradição Sinóptica, começo do Evangelho de Marcos (1,15); na tradição Paulina (Gal 4,4); e na tradição post-paulina (Ef 1,10) - e que se reveste de, caso para caso, de pequenas variações verbais e de uma polissemia cheias de subtilezas e cintilações. Analisaremos, contudo, apenas o primeiro dos três casos.

10 Que alcance tem esta fórmula e que oferece ela de peculiar na sua maneira de assinalar o tempo? Não parece inscrever-se em referência ao tempo cósmico. A que se refere então? Será que o fenómeno cristão determinou, desde o início, uma percepção original do tempo humano? 
11 A fórmula "A plenitude do tempo" surge-nos pela primeira vez no Evangelho de Marcos. Durante séculos o texto de Marcos foi considerado, por razões de natureza literária e teológica, o menos conseguido dos Evangelhos, e discutia-se mesmo se era legítimo atribuir a Marcos o estatuto de autor. 0 carácter sucinto, para não dizer escarno, da sua obra, o seu léxico vulgar e chão, num grego koinè, que os puristas se recusam a considerar língua de boa literatura, a diferença tão nítida de arquitectura quando confrontado com os outros relatos evangélicos, a ponto de se supor que verdadeiramente não tivesse nenhuma, remeteu o seu texto para uma espécie de limbo, donde praticamente só a exegese liberal o viria resgatar. Hoje, pelo contrário, não só rodeia Marcos o prestígio de ser considerado o autor da primeira narrativa evangélica e o inventor desse género literário, como se tem consciência de que a sua obra é uma verdadeira composição literária ${ }^{5}$ e querigmática. ${ }^{6}$ Para citar palavras de Étienne Trocmé: «o autor Marcos surge como o organizador que fez emergir do magma da tradição uma obra literária coerente». ${ }^{7}$ A profusão recente de estudos a este propósito sublinha bem este novo contexto.

\section{«O tempo alcançou plenitude»}

«O tempo alcançou plenitude (peplerôtai o kairòs): o Reino de Deus está próximo» (Mc 1,15) - esta é a proclamação inaugural de Jesus, a sua primeira fala enquanto personagem do relato de Marcos. Surge-nos inserida no sumário que explicita os primórdios da sua acção no território da Galileia e a mensagem por ele pregada. Este sintagma distribui-se por duas frases $(1,15)$, e cada uma articula duas orações ligadas por uma partícula copulativa:

«O tempo alcançou plenitude (peplerôtai o kairòs)

e o reino de Deus está próximo:

Convertei-vos

e acreditai no Evangelho».

13 Importa, talvez, revisitar o texto paralelo de Mateus (Mt 4,17), onde a proclamação da iniciativa de Deus aparece descrita apenas num membro: tanto a afirmação da proximidade do Reino de Deus, como a exortação à conversão. «A partir de então, Jesus começou a pregar, dizendo: "Convertei-vos, porque está próximo o Reino dos Céus"». Crêse, apesar do carácter mais elíptico do seu passo, que Mateus dependa de Marcos (pois temos coincidências textuais e de sentido significativas). Mas esta variação como que reforça o enigma que temos diante dos olhos: no fundo, o de entender então porque se elidiu a menção da plenitude do tempo, fórmula que se afigura assim, entre os evangelistas, exclusiva de Marcos, para descrever a era messiânica que emerge com Jesus.

Segundo alguns, a omissão explica-se pelo facto de Mateus ter interpretado a proclamação de Jesus não já numa perspectiva de escatologia iminente, pois quando ele escreve o seu Evangelho, numa data mais tardia, essa acentuação era tida por inadequada. Ter-se-ia entretanto passado da grande pressão de um final dos tempos iminente, para o deslindar apaziguado e sistemático de uma escatologia já realizada. Na visão do narrador mateano, o fim já aconteceu, é uma qualidade que a Páscoa de Cristo introduz no devir histórico. A preocupação em Mateus não é descrever o que está para chegar, mas como se deve viver na fidelidade àquilo que já irrompeu. Não é por acaso que, desde os Padres da Igreja, seus leitores atentos, circulava a ideia de que Mateus era sobretudo um grande projecto ético-moral.

15 A ser realmente assim, o verbo pleroô, utilizado no passivo por Marcos, num estádio mais primitivo da reflexão sobre Jesus, deve ser simplesmente compreendido no seu sentido 
primeiro: a medida do tempo esgotou-se, completou-se, nada mais pode conter. Estaríamos no mesmo âmbito de representação do tempo que encontramos em certos paradigmas messiânicos do judaísmo ou que é possível entrever na zona mais antiga da correspondência Paulina (aquela estabelecida com a comunidade de Tessalónica), onde se sublinha a expectativa de uma vinda imediata do Senhor (1 Tes 5,1-11).

Mas olhando para a direç̧ão que nos aponta o recurso verbal que Marcos adopta (a forma do perfeito, peplerôtai - alcançou plenitude, completou-se), temos um tempo onde o cumprimento começou, é verdade, mas prossegue, pois os efeitos e as repercussões do seu significado se prolongam no futuro. Isto distingue o tempo da plenitude que está em questão em Mc 1,15 de um tempo pontual e derradeiro. A reflexão que a fórmula de Marcos introduz é bem mais interessante que a linear proclamação de uma escatologia final.

\section{Do Chrónos ao Kairòs}

De facto, se é difícil discernir com precisão o que está efectivamente em jogo na proclamação inicial de Jesus baseando-se apenas no verbo pleroô, que Marcos inclusive não volta depois a empregar em relação com a categoria temporal, a utilização que ele faz do lexema kairòs pode, pelo contrário, revelar-se dirimente ou, pelo menos, iluminante. Pois, porque usa ele aqui o substantivo kairòs em vez de chrónos?

Há outras quatro passagens do Evangelho, para lá do passo de Mc 1,15, onde comparece o termo kairòs, e estas ocorrências mantêm linhas de continuidade muito curiosas e permitem uma determinação semântica unitária.

Em Mc 10,30, Kairòs designa um prazo temporal delimitado, o da existência histórica e terrena, por contraste com a duração ilimitada daquela eterna: «Quem deixar casa, irmãos, irmãs, mãe, pai, filhos ou campos por minha causa e por causa do Evangelho, receberá cem vezes mais agora, no tempo presente (nun en to kairò touto), em casas, $\mathrm{e}$ irmãos, e irmãs, e mães, e filhos, e campos, juntamente com perseguições, e, no tempo futuro, a vida eterna».

Nas restantes ocorrências, Kairòs assinala sem ambiguidades um tempo curto ou um momento particular do tempo. Assim em 11,13 onde é evocada a estação dos figos.

«Vendo ao longe uma figueira com folhas, foi ver se nela encontraria alguma coisa; mas, ao chegar junto dela, não encontrou senão folhas, pois não era tempo (o gar kairòs) de figos».

O mesmo ocorre em 12,2, numa parábola acerca dos vinhateiros:

«Um homem plantou uma vinha, cercou-a com uma sebe, cavou nela um lagar e construiu uma torre. Depois, arrendou-a a uns vinhateiros e partiu para longe. A seu tempo (to kairò) enviou aos vinhateiros um servo, para receber deles parte do fruto da vinha».

E em 13,33, num discurso de género apocalíptico, temos esta exortação final: «Tomai atenção e vigiai, porque não sabeis quando será o tempo (pote o kairòs)».

Diferente enquadramento semântico é o do termo chrónos. Não reenvia a um ponto particular, a um momento privilegiado, mas à duração, à linha contínua do tempo, aquele que se sucede e se adiciona e a propósito do qual convém o emprego de posos (quanto), que assinala a quantidade, mais do que poios (quando), o apontador da qualidade. 

semelhança de outros autores do Novo Testamento, sabe fazer a distinção entre kairòs e chrónos, uma distinção que, uma geração mais tarde, será bem expressa na opinião de um gramático notável: porção de tempo, como que um conjunto de dias contabilizados. o tempo, esse, compreende e engloba uma pluralidade de momentos. Dito de outra maneira: o kairòs exprime uma qualidade (poiotèta) do tempo, como quando dizemos «quando decorria a guerra»; o chrónos, por sua parte, designa uma quantidade (posotèta), como quando se diz «dez anos antes» ou «dez anos depois».8

O significado fundamental de kairòs é assim o de uma expressão decisiva do tempo, o seu ponto miliar, essencial. Um significado, portanto, que foge ao horizonte estritamente cronológico ${ }^{9}$ e que em autores antigos tão diversos como Sófocles ou Aristóteles, ou já na tradução grega da Bíblia Hebraica, a chamada Septuaginta, ganha, não raro, um sentido religioso, a ponto de coincidir com a revelação do próprio Deus. Também no Novo Testamento tal se irá, de certo modo, verificar, pois neste momento propício e determinante é o próprio Deus que transparece. Como escreve Bruno Forte, «não é o tempo quantificado que dará alma ao mundo [...], mas o tempo qualificado, a hora da decisão e do acolhimento da graça». ${ }^{10}$

Se Marcos efectua a distinção entre os dois termos, esta não deve ser tida em conta na interpretação da proclamação inicial de Jesus em 1,15? Lá, com efeito, é kairòs e não chrónos que é utilizado. É, por isso, preciso compreender não apenas que o tempo se prolongou até este ponto do presente, mas sobretudo que um momento privilegiado, um kairòs, acaba de ser atingido pelo facto do Reino Messiânico se ter avizinhado. $\mathrm{E} o$ advento do Messias significa que todas as coisas - e com essas o sujeito que as vê - são contagiadas pelo que emerge. Tomando uma bela expressão de Giorgio Agamben, podemos dizer que «a vocação messiânica desloca» ${ }^{11}$ os referentes do mundo.

\section{NOTAS}

1. A. CAEIRO, Poesia, Lisboa, 2001, 110.

2. D. SOUTIF, Un entretien avec Umberto Eco in Le Temps - Jounal de l'exposition «Le Temps, vite», Centre Georges Pompidou (2000), 1.

3. Cf. P. RICOEUR, Temps et récit. 3. Le temps raconté, Paris, 1985, 9.

4. I. CALVINO, Lezioni americane. Sei proposte per il prossimo millenio, Milano, 1983, 43.

5. Cf. J. RADERMAKERS, L'Évangile de Marc. Structure et théologie in M. SABBE, L'Évangile selon Marc. Tradition et redaction, Leuven, 1988,221-239.

6. Cf. N. PERRIN, The Christology of Mark, in M. SABBE, L'Évangile selon Marc. Tradition et redaction, Leuven, 1988, 471-485.

7. É. TROCMÉ, La formation de l'Évangile selon Marc, Paris, 1963, 58.

8. AMMONIUS, Peri diaphorôn lexeôn in K. NICKAU (ed.), Ammonii qui dicitur Liber De adfinium vocabulorum differentia, Leipzig, 1966, 69. 
9. Como recorda Gian Luigi Prato, o tempo «deve necessariamente fixar, na gama de um vocabulário não directamente e não propriamente cronológico, o âmbito preciso das suas acepções». Gian Luigi PRATO, Il lessico bíblico per il tempo in Humanitas, 2 (2003), 242.

10. BRUNO FORTE, Il tempo come splendore di Dio in Humanitas, 2 (2003), 306.

11. GIORGIO AGAMBEN, Il tempo che resta. Un commento alla lettera ai Romani, Torino 2000,44.

\section{RESUMOS}

Como se colocou a questão do tempo no período das origens cristãs? De que forma as primeiras comunidades apreenderam e traduziram os acontecimentos relativos a Jesus através de uma modelação própria da temporalidade? E em que medida, a própria configuração narrativa que a experiência cristã assumiu, determinou uma refiguração da realidade temporal?

A fórmula "a plenitude do tempo" (peplerotai o kairòs) surge-nos pela primeira vez no Evangelho de Marcos, um dos escritos primordiais do cristianismo primitivo. Olhando para a direcção que nos aponta o recurso verbal, temos um tempo onde o cumprimento começou, é verdade, mas que prossegue, pois os seus efeitos e repercussões prolongam-se no futuro. A reflexão que a fórmula de Marcos introduz é bem mais interessante que a linear proclamação de uma escatologia final. É preciso compreender não apenas que o tempo se prolongou até o presente, mas sobretudo que um momento privilegiado, um kairòs, acaba de ser atingido pela emergência messiânica.

How was the question of time put in the age of Christian origins? How did the first communities understand and translate events related to Jesus, through their own modelling of temporality? And how did the particular narrative configuration assumed by Christian experience determinate a refiguration of the temporary reality? One of the most important texts in primitive Christianity, Mark's Gospel presents us for the first time the formula "the plenitude of time" (peplerotai o kairòs). Looking into the direction pointed out by the verbal resource, we have a time where the fulfilment began, this is true, but where it went on, as its effects and its repercussions extend themselves into the future. The reflection introduced by Mark's formula is much more interesting than the linear proclamation of a final eschatology. We must understand not only that time extended itself to the present, but especially that a privileged moment, a kairòs, was reached by Messianic emergency.

\section{ÍNDICE}

Keywords: plenitude, kairòs, chrónos, messianic

Palavras-chave: plenitude, kairòs, chrónos, messiânico

\section{AUTOR}

\section{JOSÉ TOLENTINO MENDONÇA}

Universidade Católica Portuguesa

Licenciatura em Teologia (UCP, 1989); Licenciatura Canónica em Ciências Bíblicas (Roma, 1992); Doutoramento em Teologia Bíblica (UCP, 2004). É Professor Auxiliar na Faculdade de Teologia 
(UCP). Investigador e membro da Direcção do Centro de Estudos Religiões e Culturas. Desde 2004, Director da Revista Didaskalia. 